\title{
Does the use of per cent of predicted have any evidence base?
}

\author{
Martin R. Miller
}

Affiliation: Institute of Occupational and Environmental Medicine, University of Birmingham, Birmingham, UK.

Correspondence: Martin R. Miller, Institute of Occupational and Environmental Medicine, University of Birmingham, Birmingham, B15 2TT, UK. E-mail: martinamillermr.com

0 @ERSpublications

Researchers and journals need to apply more scrutiny to the use of \% predicted http://ow.ly/EVNvQ

Over 20 years ago there was a move to require an evidence base for the practice of medicine [1]. It is easy to understand that any new treatment or management strategy should have a firm evidence base to support its proposed use. However, implicit in a move to evidence-based practice is that one should repeatedly question all aspects of current practice to be sure, firstly, that they ever had an evidence base and, secondly, that they continue to do so.

Any search of the respiratory literature in the last 40 years will find the term "per cent of predicted" frequently appearing. Its use mainly stems from a suggestion in an eminent textbook from the 1960s that "a useful general rule is that a deviation of $20 \%$ from the predicted normal value is probably significant" [2]. The flaw in this methodology was soon exposed [3], namely that the scatter of lung function data found in the general population that is free from disease is not proportional to the mean value. Because of this, $80 \%$ of the predicted forced expiratory volume in $1 \mathrm{~s}$ (FEV1) for a male aged 40 years who is of average height $(1.77 \mathrm{~m})$ demarcates the sixth percentile but is the 14th percentile for a man of this height aged 70 years. Surprisingly, nearly 50 years on from these problems with per cent of predicted being exposed and despite a further reminder on this in the meantime [4], many clinicians and researchers remain wedded to using per cent of predicted without realising it retains age, sex and height biases that may confound their clinical management or research. In this issue of the European Respiratory Journal, QuANJER et al. [5] draw attention to how this problem may be adversely affecting the conclusions of a major study looking at the effects of air pollution on lung function [6]. QuANjer et al. [5] raise the important question "will we ever stop using [per cent of predicted]?".

The reason per cent of predicted continues to be used is probably partly due to ignorance and partly related to its widespread application in routine practice leading to a false sense of confidence from years of use. Applying $80 \%$ of predicted criteria to full lung function data sets from several laboratories across the globe was found to misclassify patients to disease categories in $>20 \%$ of patients [7]. The concern that women may be more susceptible to developing chronic obstructive pulmonary disease was based on data using per cent of predicted [8], with its inherent sex bias, and more rigorous analysis failed to demonstrate this effect [9]. The one instance where using per cent of predicted may be valid is when assessing if a change in FEV1 after bronchodilator is clinically meaningful [10] but this practice has, perhaps erroneously, now been replaced.

So an evidence base for using per cent of predicted in determining if lung function results are abnormal is absent and the approximate rule of thumb in the original proposal for using per cent of predicted [2] has not stood up to rigorous challenge. Standardised residuals (z-scores) are the validated method for making this assessment and this is the method that has been endorsed by the European Respiratory Society for $>20$ years $[11,12]$. If we are to avoid the respiratory literature including work that can be challenged in the

Received: Oct 272014 | Accepted after revision: Nov 212014

Conflict of interest: None declared.

Copyright OERS 2015 
future because of the errors inherent in using per cent of predicted, then researchers and journals need to apply more scrutiny to its use, and we need more studies using alternative strategies so that we and our patients are better informed.

\section{References}

1 Guyatt G, Cairns J, Churchill D, et al. Evidence-based medicine. A new approach to teaching the practice of medicine. JAMA 1992; 268: 2420-2425.

2 Bates DV, Christie RV. Respiratory Function in Disease. An Introduction to the Integrated Study of the Lung. Philadelphia, WB Saunders, 1964.

3 Sobol BJ, Weinheimer B. Assessment of ventilatory abnormality in the asymptomatic subject: an exercise in futility. Thorax 1966; 21: 445-449.

Miller MR, Pincock AC. Predicted values: how should we use them? Thorax 1988; 43: 265-267.

Quanjer PH, Cooper B, Ruppel GL, et al. Defining airflow obstruction. Eur Respir J 2015; 45: 561-562.

Smith M, Li L, Augustyn M, et al. Prevalence and correlates of airflow obstruction in 317000 never-smokers in China. Eur Respir J 2014; 44: 66-77.

7 Miller MR, Quanjer PH, Swanney MP, et al. Interpreting lung function data using $80 \%$ predicted and fixed thresholds misclassifies more than $20 \%$ of patients. Chest 2011; 139: 52-59.

8 Gan WQ, Man SF, Postma DS, et al. Female smokers beyond the perimenopausal period are at increased risk of chronic obstructive pulmonary disease: a systematic review and meta-analysis. Respir Res 2006; 7: 52.

9 Jordan RE, Miller MR, Lam KB, et al. Sex, susceptibility to smoking and chronic obstructive pulmonary disease: the effect of different diagnostic criteria. Analysis of the Health Survey for England. Thorax 2012; 67: 600-605.

10 Eliasson O, Degraff AC. The use of criteria for reversibility and obstruction to define patient groups for bronchodilator trials. Influence of clinical diagnosis, spirometric, and anthropomorphic variables. Am Rev Respir Dis 1985; 132: 858-864.

11 Quanjer PH, Tammeling GJ, Cotes JE, et al. Lung volumes and forced ventilatory flows. Eur Respir J 1993; 6 : Suppl. 16, 5-40.

12 Pellegrino R, Viegi G, Brusasco V, et al. Interpretative strategies for lung function tests. Eur Respir J 2005; 26 : 948-968. 